\title{
Orbital Floor Fractures: Epidemiological, Clinical and Therapeutical Study at Sylvanus Olympio University Teaching Hospital in Lomé about 51 Cases
}

\author{
Saliou Adam1,2*, Hamza Dolès Sama ${ }^{3}$, Yao Messanvi Akpoto ${ }^{4}$, Haréfétéguéna Bissa ${ }^{1,2}$, \\ Palakina Agoda ${ }^{5}$, Winga Foma ${ }^{2}$, Essobozou Plaoudézina Pegbessou ${ }^{6}$, Bathokédéou Amana², Es- \\ sohanam Boko', Eyawèlohn Kpemissi²
}

\author{
${ }^{1}$ Department of Stomatology and Maxillofacial Surgery, Sylvanus Olympio University Teaching Hospital of Lomé, Togo \\ ${ }^{2}$ Department of ENT, Sylvanus Olympio University Teaching Hospital of Lomé, Togo \\ ${ }^{3}$ Department of Anesthesia and Intensive Care, Sylvanus Olympio University, Togo \\ ${ }^{4}$ Military Medical Department, Sylvanus Olympio University Teaching Hospital of Lomé, Togo \\ ${ }^{5}$ Department of Stomatology, Campus University Teaching Hospital of Lomé, Togo \\ ${ }^{6}$ Department of ENT, Campus University Teaching Hospital of Lomé, Togo \\ Email: *saliou.adam1@yahoo.com
}

How to cite this paper: Adam, S., Sama, H.D., Akpoto, Y.M., Bissa, H., Agoda, P., Foma, W., Pegbessou, E.P., Amana, B., Boko, E. and Kpemissi, E. (2021) Orbital Floor Fractures: Epidemiological, Clinical and Therapeutical Study at Sylvanus Olympio University Teaching Hospital in Lomé about 51 Cases. Open Journal of Stomatology, 11, 373-386.

https://doi.org/10.4236/ojst.2021.119033

Received: August 11, 2021

Accepted: September 19, 2021

Published: September 22, 2021

Copyright ( 2021 by author(s) and Scientific Research Publishing Inc. This work is licensed under the Creative Commons Attribution International License (CC BY 4.0).

http://creativecommons.org/licenses/by/4.0/ (c) (i) Open Access

\begin{abstract}
Introduction: Orbital floor fractures are a significant pathology among maxillofacial injuries. They can cause oculomotor, sensory, and sometimes esthetic disorders. The goal of this study was to determine the epidemiological profile of orbital floor fractures and show their clinical and therapeutic approach in Lomé. Patients and method: This was a descriptive retrospective study of orbital floor fractures collected in the ENT and maxillofacial surgery department of Sylvanus Olympio University Hospital in Lomé over 8 years (January 1, 2011 to December 31, 2018). Results: We reviewed 63 cases of orbital floor fractures out of 552 cases of facial trauma. According to the inclusion and non-inclusion criteria, we retained 51 cases. The hospital frequency of orbital floor fractures was $9.24 \%$ of facial fractures. The average age of the patients was $35 \pm 10.34$ years. Males were predominant (ratio $=7.5$ ). The main etiology was road accidents $(92.16 \%)$. Ophthalmological signs were dominated by vertical diplopia (31.37\%), limited eye movement (25.49\%), and enophthalmia (29.41\%). The sensory sign was dominated by suborbital hypoesthesia $(13.73 \%)$. Surgical treatment was performed in $86.27 \%$ of patients. The average intervention time was $17.84 \pm 12.69$ days after the trauma. The main approach was the subciliary route (65.91\%). The surgical procedures consisted of muscle and fat removal (20.45\%) and orbital floor repair
\end{abstract}


by mesh plate $(50 \%)$. The average length of hospitalization was $9.63 \pm 5.23$ days. Surgical site infection was the main postoperative complication observed in $3.92 \%$ of patients. The main sequelae were diplopia (4.55\%), suborbital hypoesthesia (4.55\%), and enophthalmos (4.55\%). Conclusion: Orbital floor fractures are mainly due to road accidents. Management must be multidisciplinary and adequate in order to avoid irreversible functional and/or morphological sequelae. Their prevention consists of effective combat of road accidents.

\section{Keywords}

Orbital Floor, Fracture, Diplopia, Facial Bone, Road Accidents, Lomé (Togo)

\section{Introduction}

Orbital floor fractures are common and mainly affect young adult males [1] [2]. They occur during road accidents, aggressions, fights, or sports accidents [1] [3]. Classically, two types can be distinguished: "Blow-out" fractures, and "trap-door" fractures.

Blow-out fractures or orbital floor collapse fractures occur by two main mechanisms, indirect or direct [4] [5]. For the indirect or hydraulic mechanism, this is a trauma carried to the eyeball by a blunt object which diameter is equal to that of the orbital frame, during a frontal impact, the eyelids being closed. This shock displaces the contents of the orbit backward and causes a sudden increase in intra-orbital pressure [4]. The zones of least resistance then break, in particular the floor of the orbit which is only $0.5 \mathrm{~mm}$ thick. For the direct mechanism, the shock is carried on the inferior orbital rim. Two possibilities can arise: either the rim breaks but without displacement and the fracture radiates to the floor of the orbit (impure blow-out), or the orbital rim bends without breaking, and the orbit floor collapses under the shock wave (pure blow-out) [4].

The "trap-door" fracture is a fracture of a small extent. It draws its individuality from the importance of oculomotor disorders which risk becoming definitive if no surgical intervention is undertaken urgently [6].

The diagnosis of these fractures is suspected based on clinical signs, and confirmed by radiological explorations. The exploration of ocular motility is the first-line study. If this exploration confirms diplopia, it must be supplemented by the Hess Lancaster test which allows to quantification of any diplopia of unresolved neurogenic or myogenic origin, by indicating the antagonist muscles [7] [8]. The ophthalmologic examination should be systematic to look primarily for ocular involvement as well as disturbances in the sensitivity of the infraorbital nerve which may be due to damage of this nerve in the infraorbital canal [9].

Radiologically, the importance of Blondeau's incidence has greatly decreased in favor of recent CT-Scan techniques. However, this exploration still has a place in facial trauma because it allows to exploration of the orbital floors and the 
maxillary sinuses and sometimes to visualize the "drop" image suspended in the maxillary sinus. CT-Scan with images of two- and three-dimensional reconstructions allow the diagnosis and assessment of lesions in the acute phase and in the sequelae stage [10].

The treatment of floor fractures aims to ensure reconstruction of the floor of the orbit as close as possible to its original anatomy, to extricate the incarcerated soft tissues, to manage eye and eyelid lesions if necessary, and to treat the others associated lesions [9]. The main goal of this study was to describe the epidemiological, lesional and therapeutic aspects of orbital floor fractures in Lomé.

\section{Patients and Method}

We carried out a descriptive retrospective study over a period of 8 years (January 1, 2011 to December 31, 2018) in the department of Otorhinolaryngology, Neck and Maxillo-Facial Surgery (ENT-CCMF) of the Sylvanus Olympio University Teaching Hospital (CHU SO) in Lomé. The study focused on the charts of patients who were managed for maxillofacial trauma with an orbital floor fracture confirmed by facial CT-Scan. A pre-established individual information sheet permitted the collection of data. The main variables studied were age, sex, profession, patients' residence, etiologies of the trauma, clinical manifestations, results of radiological explorations, medical and/or surgical treatment received, and evolution after treatment. We excluded from the study patients with incomplete charts and outpatients. The data collected were entered using Word 2016 software and processed using Excel 2016 and Epi Info 7.2 software.

\section{Results}

\subsection{Epidemiological Aspects}

\subsubsection{Hospital Frequency of Orbital Floor Fractures}

We reviewed 63 cases of orbital floor fractures out of 552 cases of facial trauma. According to the inclusion and non-inclusion criteria, we retained 51 cases, that is a hospital frequency of $9.24 \%$.

\subsubsection{Distribution of Patients by Age Group and Sex}

The mean age of the patients was $35 \pm 10.34$ years with the extremes of 17 years and 63 years. Eighteen patients (35.30\%) were between 30 and 39 years old (Figure 1). The sex ratio was 7.5 with $88.24 \%$ male patients and $11.76 \%$ female.

\subsubsection{Distribution of Patients by Profession and Lifestyle}

Twelve patients (23.53\%) were motorcycle taxi drivers. The category of workers and craftsmen represented $17.65 \%$ of cases (Table 1). Of the patients, $27.45 \%$ were alcohol users. Tobacco use has not been reported.

\subsubsection{Distribution of Patients by City and by Originating Hospital}

The majority of patients $(58.82 \%)$ came from Lomé and its surroundings (Table 2). Nineteen patients (37.25\%) came from the Regional Hospital Centers (CHR) of Togo (Figure 2). 


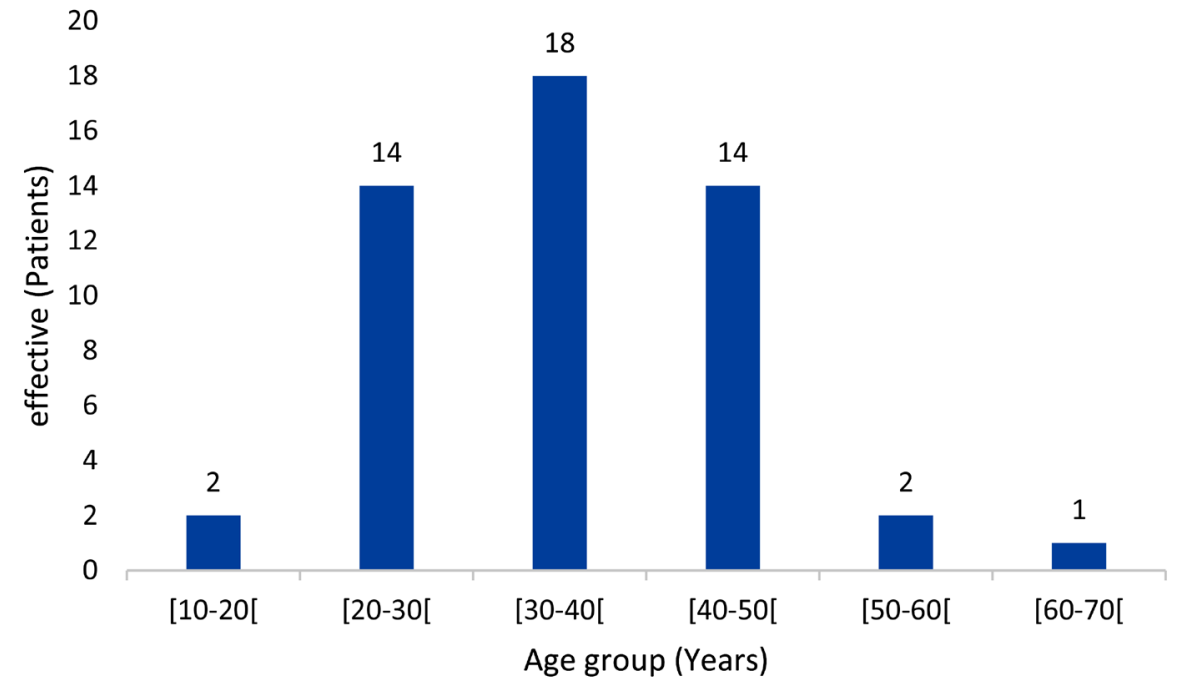

Figure 1. Distribution of patients by age group.

Table 1. Distribution of patients by profession.

\begin{tabular}{ccc}
\hline & Effective & Percentage (\%) \\
\hline Motorcycle-taxi driver & 12 & 23.53 \\
Worker/Craftsman & 9 & 17.65 \\
Pupil/Student & 7 & 13.73 \\
Trader & 6 & 11.67 \\
Farmer/Breeder & 5 & 9.90 \\
Teacher & 4 & 7.84 \\
Military & 2 & 3.92 \\
Health worker & 2 & 3.92 \\
Housewife & 2 & 3.92 \\
Religious & 2 & 3.92 \\
Total & $\mathbf{5 1}$ & 100
\end{tabular}

Table 2. Distribution of patients according to the city of origin.

\begin{tabular}{ccc}
\hline & Effective & Percentage (\%) \\
\hline Lomé & 30 & 58.82 \\
Sokodé & 4 & 7.86 \\
Atakpamé & 3 & 5.88 \\
Dapaong & 3 & 5.88 \\
Notsè & 3 & 5.88 \\
Kara & 2 & 3.92 \\
Kpalimé & 2 & 3.92 \\
Tsévié & 2 & 3.92 \\
Afagnan & 1 & 1.96 \\
Vogan & 1 & 1.96 \\
Total & 51 & 100 \\
\hline
\end{tabular}




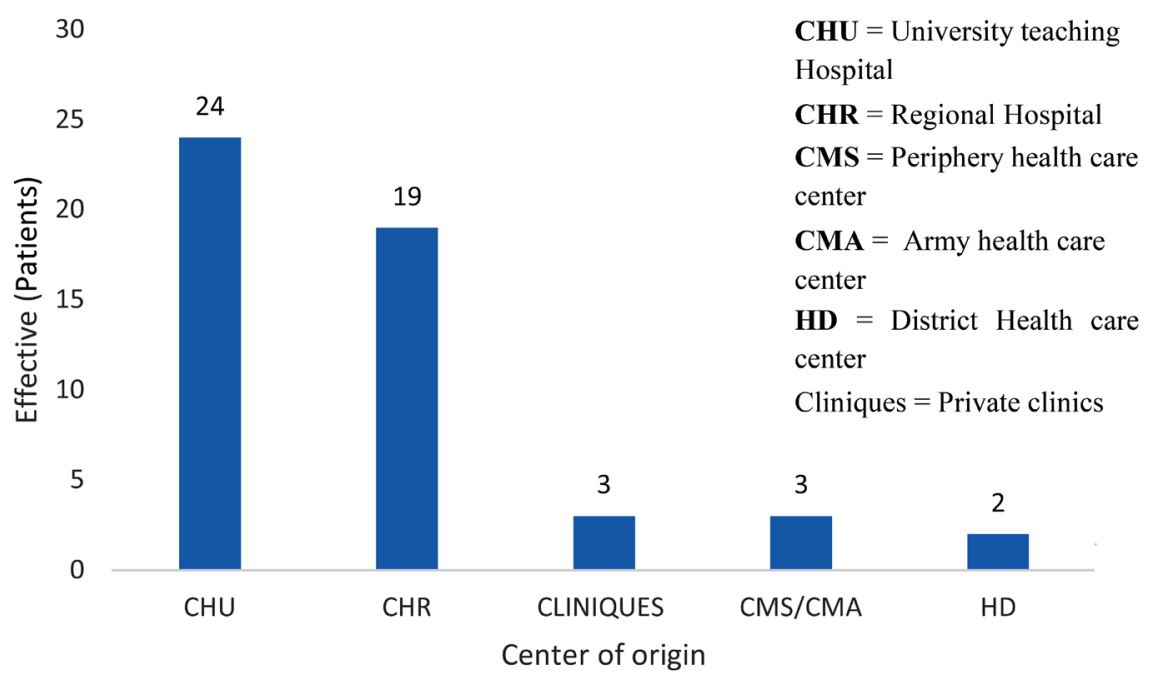

Figure 2. Distribution of patients according to the center of origin.

\subsection{Clinical Aspects}

\subsubsection{Circumstances of the Trauma}

Public road accidents (AVP) were the most common etiology (92.16\%). The other circumstances of occurrence were brawl accidents (3.92\%), work accidents (1.96\%) and sports accidents (1.96\%).

\subsubsection{Patient Itinerary before Admission to the ENT-CCMF Department} All the patients had been taken care of in the surgical emergency departments of the various health care centers within 24 hours, including nine (17.65\%) in the first six hours.

Forty-seven patients $(92.16 \%)$ were referred directly to ENT-CCMF after first aid. Two patients $(3.92 \%)$ required resuscitation in the multipurpose intensive care unit of the CHU SO and two other patients (3.92\%) were hospitalized in the neurosurgery department for severe cranio-encephalic trauma. They were transferred to ENT-CCMF after stabilization, for further treatment.

The average time between the occurrence of the trauma and admission to a specialized Department was $9.25 \pm 8.16$ days with extremes of 24 hours and 55 days. Thirty patients (58.82\%) were admitted to ENT-CCMF during the first week after the trauma, of which four patients were admitted within 24 hours after the trauma (Figure 3).

\subsubsection{Clinical Assessment}

The right and left eyes were involved in trauma to the floor of the orbit, respectively, in $52.94 \%$ and $45.10 \%$ of cases. In $1.96 \%$ of cases, the involvement was bilateral. Sensory signs were dominated by infraorbital hypoaesthesia found in $13.73 \%$ of cases. An ophthalmological consultation was performed in $92.16 \%$ of patients; the others were unable to honor this consultation for financial reasons. It allowed to objectifying: Vertical diplopia (31.37\%), enophthalmos (29.41\%), limitation of eye movements (25.49\%), subconjunctival hemorrhage (25.49\%), an upper eyelid wound (25.49\%), eyelid edema (23.53\%), conjunctival hyper- 
emia (19.61\%) and an eyeball wound (7.84\%). No patient had received a Hess Lancaster test, whether or not they had diplopia after the trauma. The other associated clinical signs are listed in Table 3.

\subsection{Radiological Aspects}

\subsubsection{X-Ray Blondeau's Incidence}

$\mathrm{X}$-ray Blondeau's incidence was requested and performed in one patient but supplemented by facial CT-Scan as it did not show the lesions.

\subsubsection{Facial CT-Scan}

Facial CT-Scan was performed in all patients in axial, coronal and threedimensional reconstructions. The suggestive signs found were maxillary hemosinus (100\%) and pneumorbitis (1.96\%). The direct radiological signs observed were: simple cracking of the orbital floor (51.92\%), "trap-door" fracture (28.85\%), a "pure blow-out" fracture (11.54\%) and impure Blow-out fracture (7.69\%). The other associated fractures are summarized in Table 4. A blow-out fracture is showed in Figure 4.

\subsection{Therapeutic Aspects}

\subsubsection{Medical Treatment}

All patients received medical treatment based on analgesics, steroidal or non-steroidal

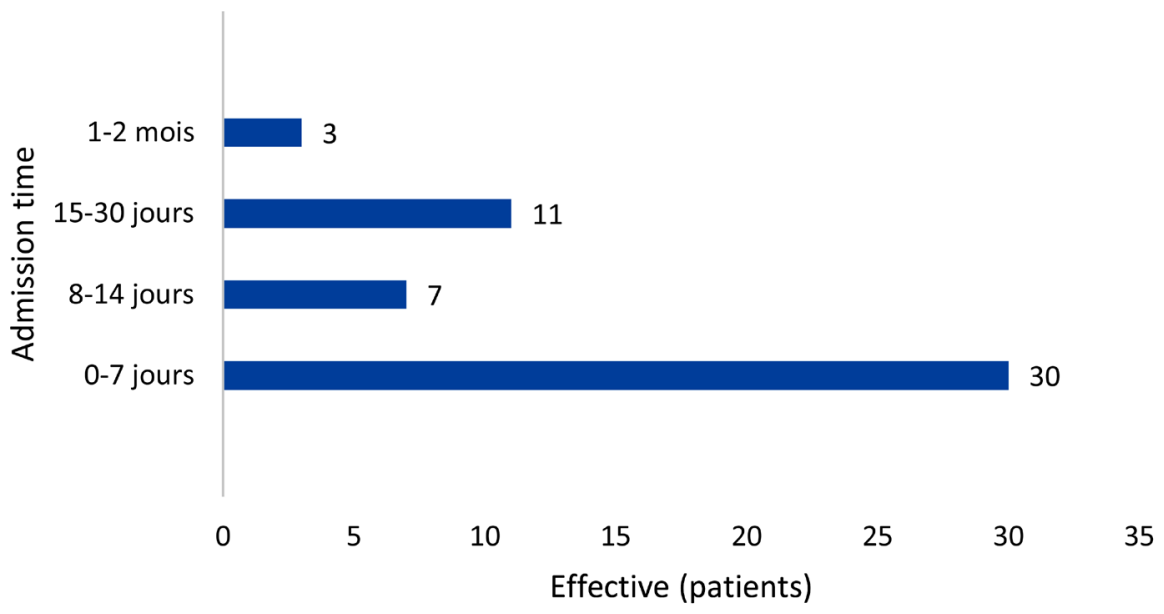

Figure 3. Distribution of patients according to ENT-CCFM admission time.

Table 3. Distribution of patients according to associated clinical signs.

\begin{tabular}{ccc}
\hline & Effective & Percentage (\%) \\
\hline Periorbital ecchymosis & 50 & 98.04 \\
Hematoma or edema & 48 & 94.12 \\
Deviation of the nasal pyramid & 15 & 29.41 \\
Dermabrasion & 14 & 27.45 \\
Epistaxis & 13 & 25.49 \\
Cheekbone erasure & 4 & 7.84 \\
\hline
\end{tabular}


Table 4. Distribution of patients according to the associated lesions.

\begin{tabular}{ccc}
\hline & Effective & Percentage (\%) \\
\hline Zygomatic body fracture & 34 & 65.38 \\
Fracture of the inferior orbital rim & 32 & 61.54 \\
Maxillary fracture & 27 & 51.92 \\
Fracture of the other walls of the axillary sinus & 22 & 42.31 \\
Fracture of nose bone & 14 & 26.92 \\
Fracture of the medial wall of the orbit & 11 & 21.15 \\
Lefort II fracture & 7 & 13.46 \\
Lefort III fracture & 5 & 9.62 \\
Lefort I fracture & 5 & 9.62 \\
Orbit roof fracture & 4 & 7.69 \\
Fracture of the lateral wall of the orbit & 2 & 3.85 \\
\hline
\end{tabular}

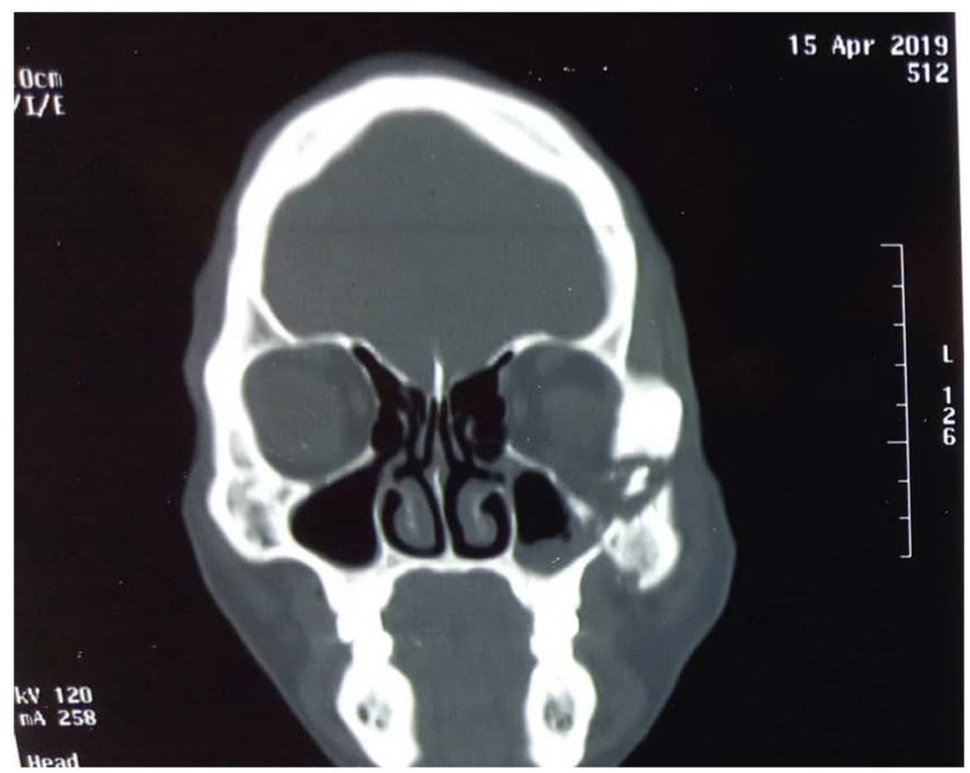

Figure 4. CT image in coronal section showing collapse of the left orbital floor + fracture of the left zygomatic body.

anti-inflammatory drugs and antibiotic prophylaxis based on beta-lactams, whether or not associated with imidazoles. Previous tamponade was performed in thirteen patients $(25.49 \%)$ with minimal epistaxis. Tetanus antitetanus serovaccination was performed routinely in all patients.

\subsubsection{Surgical Treatment}

Twenty-three patients (45.09\%) had an upper eyelid wound sutured and surgery was performed in forty-four patients (86.27\%).

1) Surgical management time after the trauma

The mean time between the trauma and the surgical management of the patients was $17.84 \pm 12.69$ days with extremes of 5 days and 60 days. Seventy-five 
percent of the patients were operated on beyond the second week following the trauma (Figure 5).

\section{2) Surgical technique}

All patients were operated on under general anesthesia.

\subsubsection{Operative Approach}

The surgical approaches were the sub-ciliary approach (65.91\%), the eyelid-cheek approach (25\%) and the operative route through the wound (9.09\%). Figure 6 presented a sub-ciliary approach, and Figure 7, the result after immediate operative time.

\subsubsection{Technical Procedure}

Muscle and fat extrication followed by forced sucking were performed in nine patients (20.45\%) who presented with a "trap-door" fracture. Orbital floor repair was performed using a titanium mesh plate in twenty-two patients (50\%). The patients also benefited from the repair of the associated lesions (Table 5).

\subsection{Results}

The mean length of hospitalization after the operation was $9.63 \pm 5.23$ days with

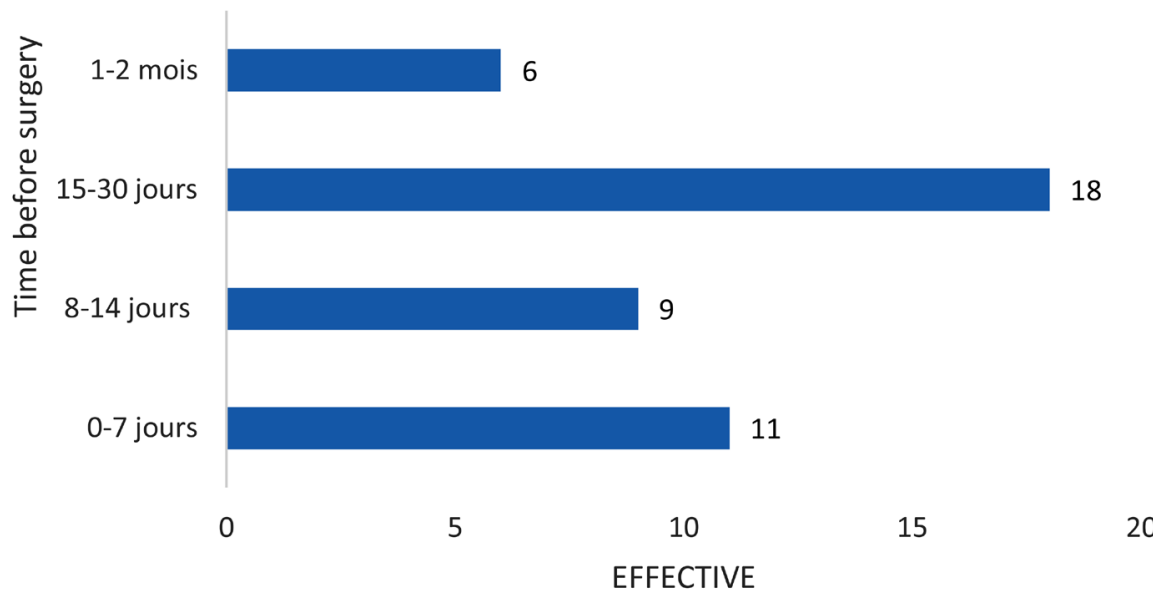

Figure 5. Distribution of patients according to the time before surgery.

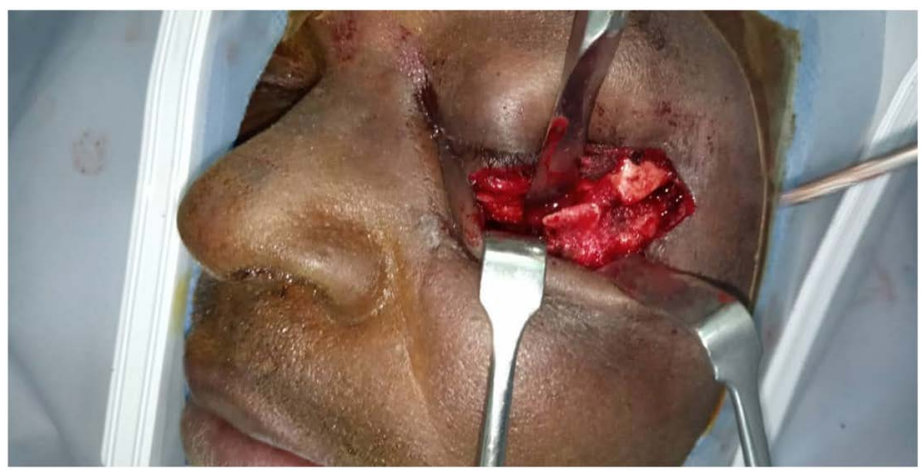

Figure 6. Intraoperative image showing the approach to the orbital floor via the subciliary approach. 
extremes of 4 days and 25 days. There had been no intraoperative incident. Periorbital edema and ecchymosis were noted in all patients immediately postoperatively and progressed favorably with symptomatic treatment. The late postoperative complications noted were infections of the operative site objectified in two patients $(4.55 \%)$ and who were treated with antibiotic therapy adapted to the germs involved.

\subsection{Sequelae}

The postoperative check-up was performed at 15 days, 6 weeks, 3 months, 6 months and 12 months after the operation for clinical and radiological checks. Six patients (13.65\%) presented sequelae such as diplopia, enophthalmos and suborbital hypoaesthesia (Table 6). These patients did not come for check-up after the sixth week postoperative.

\section{Discussion}

\subsection{Patients and Method}

This is a descriptive retrospective study, carried out on the epidemiological, clinical

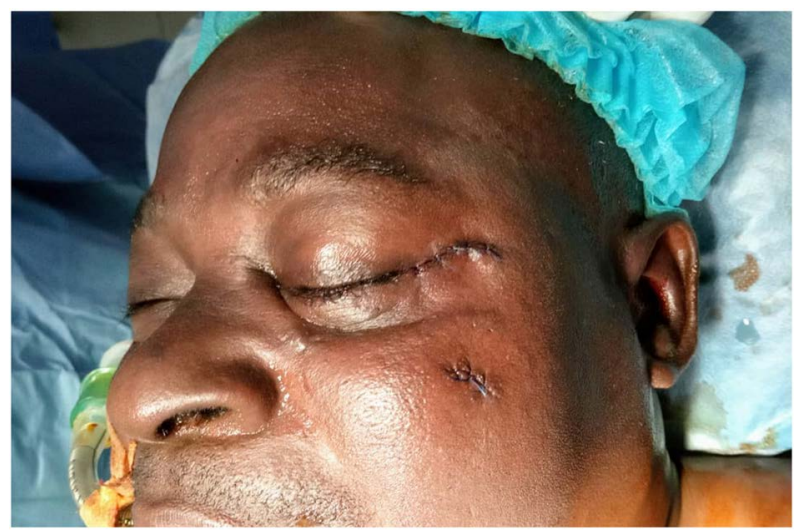

Figure 7. Immediate postoperative image after sub-ciliary approach.

Table 5. Distribution of patients according to the surgical procedure.

\begin{tabular}{ccc}
\hline & Effective & Percentage (\%) \\
\hline Osteosynthesis of the infraorbital rim by screwed plate & 37 & 84.09 \\
Orbital floor repair by mesh plate & 13 & 29.55 \\
Muscle and fat extrication + repair of the orbital floor by mesh plate & 9 & 20.45 \\
\hline
\end{tabular}

Table 6. Distribution of sequelae according to the types of lesions.

\begin{tabular}{cccc}
\hline & Operative indication & Effective & Percentage (\%) \\
\hline $\begin{array}{c}\text { Persistence of suborbital } \\
\text { hypoaesthesia }\end{array}$ & Impure blow-out \\
Vertical diplopia & Traporbital hypoaesthesia & 2 & 4.55 \\
Residual enophthalmos & Impure blow-out + enophthalmos & 2 & 4.55 \\
\hline
\end{tabular}


and therapeutic aspects of 51 cases of orbital floor fractures collected in the ENT-CCMF department of the University Teaching Hospital of Lomé (CHU $\mathrm{SO})$. The sample of 51 patients seems to be underestimated since some incomplete files were rejected due to the absence of the key variables necessary for the study. In addition, for personal reasons, some patients are taken care of in private clinics in the city. The other limitation of this study is that it could have concerned the Ophthalmology department of CHU SO where some patients could consult directly because of eye disorders related to these traumas. But anyway, most of these patients seen in the ophthalmology department are sent back to the maxillofacial surgery department, after consultation for management of disorders related to orbital bone trauma. In the University Teaching Hospital of Lomé, there is no possibility to make Hess Lancaster test, because of lack of materials. Notwithstanding these extenuating circumstances, the results of this work have undeniably allowed taking stock of these traumas and their management in Togo.

\subsection{Epidemiological Aspects}

The hospital frequency of orbital floor fractures in our series was $9.24 \%$ of all maxillofacial injuries. This prevalence is almost similar to those reported by Biaou et al. in Benin in 2003 [2] and by Méda et al. in Burkina faso in 2001 [5]. In the Western literature, the frequency of orbital floor fractures is higher and varies from $10 \%$ to $20 \%$ [3] [4] [11]. These relatively low frequencies in African studies could be explained on the one hand by insufficient health care centers, and on the other hand by financial difficulties which force some patients to seek treatment at home or from traditional healers.

With an average age of 35 years (extremes: 17 years and 63 years), the age group most affected in our series was $30-39$ years (35.30\%). Similar results are reported by several authors in the literature [2] [5] [11]. These results lead to the conclusion that maxillofacial trauma is the prerogative of young adults who are most often males. In fact, in our series, the male sex was predominant, with a sex ratio of 7.5. Biaou et al. [2] in Benin reported the same sex ratio. Several studies have reported this male predominance in maxillofacial trauma in general, even if it seems less important. Munos et al. [12] and Gear et al. [13] reported 4. This high predominance of young adult males could be explained by the fact that it is the most active age group, especially in the most exposed professions: Taximotorcycle drivers, taxis, construction workers trades; to which they sometimes work in drunkenness conditions (27.45\%).

\subsection{Clinical Aspects}

In our study, as in most African studies, road accidents are the primary causes of orbital floor fractures [2] [5]. However, in Western countries, other etiologies are more likely to cause these lesions. Thus, sports accidents were ranked first according to Tang et al. [14] in Canada and Piombino et al. [15] in Italia. For 
Senese et al. in Belgium [16], assaults were in the majority. Many factors could explain this high frequency of road accidents in the African studies. In fact, habits such as the compulsory wearing of helmets and seat belts by road users, and road safety measures are not observed in Africa. In addition, the growth of public transport (high-speed trains, subways, buses, etc.) is still rudimentary there. To these different causes can be added the increase in the vehicle fleet with the rapid development in recent decades of the use of two-wheeled vehicles; which is not followed by the modernization of road infrastructures [2] [5].

The diagnosis of orbital floor fractures is suspected based on clinical signs, and confirmed by radiological explorations. The clinical examination should begin with the exploration of ocular motility. This exploration should be supplemented by the Hess Lancaster test for diplopia [7]. The limitation of eye movements was most often in the vertical upward gaze, sometimes in the outward gaze, thus reflecting incarceration of the periorbital soft parts [2] [7]. Its frequency in our series is $25.49 \%$. It represented the most important sign in the series of Tang et al. [14] with a frequency of $45 \%$. As for diplopia, it was noted in $31.37 \%$ of our patients. Its frequency in the literature is estimated between 25 to $75 \%$ [14] [15]. Enophthalmos was found in $29.41 \%$ of cases in our study. It is thought to be linked to an increase in orbital volume or the displacement of the soft contents of the orbit in the maxillary sinus. Its frequency is high in blow-out fractures and varies according to the studies [14] [15]. Thus, diplopia, enophthalmia and limitation of eye movements are the main signs of fractures of the floor of the orbit. They are often associated with hypoesthesia in the area of the infraorbital nerve [9] [17]. For medico-legal reasons, Gas et al. [18] recommend their systematic research before and after any surgery.

Apart from these major signs, there are less specific ophthalmologic signs which are frequently encountered in trauma to the orbit. The most frequent manifestations in our study were subconjunctival hemorrhage (25.49\%), conjunctival hyperemia, globe sore, edema, and upper eyelid sore. These clinical manifestations have been reported by various authors and are thought to be linked to the close relationship of the eye to the orbital floor [2] [18].

The facial CT-Scan with axial and coronal slices and images of two and three-dimensional reconstructions allows diagnosis and complete lesions assessment [10] [18]. Comparative studies between standard radiography on the one hand [10] and MRI on the other hand [19] with CT-Scan have shown the superiority of the latter in bone lesions of the floor of the orbit. For Gas et al. [18], the indication for facial CT-Scan should be very broad or even almost systematic in any trauma of the face to minimize forgeting lesions which could lead functional and/or aesthetic disorders. The CT-Scan makes it possible to specify the therapeutic indications and the type of intervention [19]. As for the incidence of Blondeau, its importance has greatly diminished in favor of recent CT-Scan techniques. However, it still has a place in facial trauma because it makes it possible to highlight certain indirect signs and possibly direct signs of orbital floor fractures. Sometimes these are images of unraveling which are taken 
systematically in the emergency room and therefore supplemented later by more appropriate explorations, as CT-Scan in particular.

\subsection{Therapeutic Aspects}

Treatment of orbital floor fractures is aimed at relieving the injured person, reconstructing the orbital floor, treating associated lesions and avoiding complications. It combines medical treatment systematically and surgical treatment as needed.

Medical treatment includes the use of analgesics, steroidal or non-steroidal anti-inflammatory drugs, and broad-spectrum antibiotics. The systematic use of antibiotics in our treatment is consistent with the work of Shuttleworth et al. [20] who recommended that all patients with orbital trauma should receive prophylactic antibiotics to prevent the risk of possible orbital cellulitis. In our context, this attitude was justified especially since there were associated skin lesions. In addition, the health care conditions are precarious in our context; then an infection could occur secondarily, complicating the initial lesions.

Surgical treatment ensures reconstruction of the orbital floor as close as possible to its initial anatomy, frees the incarcerated soft tissues, and if necessary manages eye and eyelid lesions and other associated lesions. In our study $86.27 \%$ of patients received surgical treatment; abstention from treatment being justified whenever the orbital floor fracture was not accompanied by morphological and functional signs, and whenever the CT-Scan signs were minimal as recommended by Roth et al. [21]. For some authors, this surgery must be early in the first hours following the trauma [22] in order to facilitate the surgical procedure and limit the functional sequelae. For others, this surgical management is justified after the edema has gone away, as this can be achieved in 3 to 7 days with an anti-edema drug [6] [23]. In our study, these functional sequelae were objectified in $13.65 \%$ of patients and are linked to the delay before surgical management (18 days on average). These delays before treatment can be explained by the financial difficulties of patients and the lack of specialized centers for the treatment of these lesions in our health care centers. In well-equipped countries, treatment times are short [17] [22] [23] with better results.

\section{Conclusion}

Orbital floor fractures are common among maxillofacial trauma. Our study allowed us to show the epidemiology of these lesions as well as their clinical aspects and the modalities of their management in Togo. Like all maxillofacial trauma, orbital floor fractures are the preserve of young adult males. The most frequent causes are road accidents involving motorcyclists in particular. Under our working conditions, the repair of the orbital floor in the event of a collapse is carried out mainly with titanium mesh plates. However, as an alternative, the prolene mesh could most certainly be a material of choice for small-area loss of substances from the orbital floor. The delay in surgical management in some pa- 
tients has been the source of both aesthetic and functional sequelae: Enophthalmos, diplopia, and suborbital hypoaesthesia.

\section{Conflicts of Interest}

The authors declare no conflicts of interest regarding the publication of this paper.

\section{References}

[1] Lahbabi, M., Lockhart, R., Fleuridas, G., Chikhani, L., Bertrand, J.C. and Guilbert, F. (1999) Enophtalmies post-traumatiques: Considérations physiopathologiques et thérapeutiques actuelles. Revue de Stomatologie et de Chirurgie Maxillo-Faciale, 100, 165-174.

[2] Biaou, O., Adjibabi, O., Biotchane, I., Alamou, S., Ouedraogo, B., Alao, N. and Hounkpè, Y.Y.C. (2003) Fractures du plancher de l'orbite: Prise en charge à la clinique mutualiste de Cotonou. Bénin Medical, 24, 44-47.

[3] Koh, V., Chiam, N. and Sundar, G. (2014) Survey of Common Practices among Oculofacial Surgeons in the Asia-Pacific Region: Management of Orbital Floor Blow-Out. Craniomaxillofacial Trauma \& Reconstruction, 7, 197-202. https://doi.org/10.1055/s-0034-1371774

[4] Barry, R., Wolbert, T.T., Mozaffari, F. and Ray, P.D. (2018) The Impact of Age, Injury Severity, and Mechanism on Orbital Blow-Out Fracture Patterns after Blunt Trauma: An 11 Year Review. Plastic and Reconstructive Surgery-Global Open, 6, 49. https://doi.org/10.1097/01.GOX.0000546779.03737.04

[5] Meda, N., Ouedraogo, A., Daboue, A., Ouedraogo, M., Ramde, B. and Some, D. (2001) Etiologies des traumatismes oculo-palpébraux au Burkina Faso. Journal Français D' Ophtalmologie, 24, 463-466.

[6] Gola, R., Nerini, A. and Jallut, Y. (1992) Une fracture piège, la fracture en trappe du plancher de l'orbite. Annales de Chirurgie Plastique Esthétique, 27, 332-340.

[7] Laurentjoye, M., Bondaza, M., Majoufre, C., Huslin, V., Caix, P. and Ricard, A.S. (2014) Quand demander un examen orthoptique dans la prise en charge des fractures du plancher de l'orbite. Revue de Stomatologie et de Chirurgie Maxillo-Faciale, 26, 112-119. https://doi.org/10.1016/j.revsto.2014.07.005

[8] Pang, S.S.Y., Fang, C. and Chan, J.Y.W. (2018) Application of Three-Dimensional Printing Technology in Orbital Floor Fracture Reconstruction. Trauma Case Reports, 17, 23-28. https://doi.org/10.1016/j.tcr.2018.09.006

[9] Futran, N.D., Farwell, D.G., Smith, R.B., Johnson, P.E. and Funk, G.F. (2005) Definitive Management of Severe Facial Trauma Utilizing Free Tissue Transfer. Otolaryngology-Head and Neck Surgery, 132, 75-85.

https://doi.org/10.1016/j.otohns.2004.08.013

[10] Bhattacharya, J., Moseley, I.F. and Fells, P. (1997) The Role of Plain Radiography in the Management of Suspected Orbital Blow-Out Fractures. The British Journal of Radiology, 70, 29-33. https://doi.org/10.1259/bjr.70.829.9059291

[11] Bande, C.R., Daware, S., Lambade, P. and Patle, B. (2015) Reconstruction of Orbital Floor Fractures with Autogenous Bone Graft Application from Anterior Wall of Maxillary Sinus: A Retrospective Study. Journal of Maxillofacial and Oral Surgery, 14, 605-610. https://doi.org/10.1007/s12663-014-0716-7

[12] Munos, M.F., Perez, J.S. and Rodriguez-Campo, F.J. (2000) Reconstruction of Orbital Fractures with Dehydrated Human Dura Mater. Journal of Oral and Maxil- 
lofacial Surgery, 58, 1361-1366. https://doi.org/10.1053/joms.2000.18266

[13] Gear, A.J.L., Lokeh, A., Aldridge, J.H., Migliori, M., Benjamin, C. and Schubert, W. (2002) Safety of Titanium Mesh for Orbital Reconstruction. Annals of Plastic Surgery, 48, 1-9. https://doi.org/10.1097/00000637-200201000-00001

[14] Tang, D.T., Lalonde, J.F. and Lalonde, D.H. (2011) Delayed Immediate Surgery for Orbital Floor Fractures: Less Can Be More. The Canadian Journal of Plastic Surgery, 19, 125-128. https://doi.org/10.1177/229255031101900402

[15] Piombino, P., Laconetta, G., Ciccarelli, R., Romeo, A., Spinzia, A. and Califano, L. (2010) Repair of Orbital Floor Fractures: Our Experience and New Technical Findings. Craniomaxillofacial Trauma \& Reconstruction, 3, 217-222. https://doi.org/10.1055/s-0030-1268518

[16] Senese, O., Boutremans, E., Gossiaux, C., Loeb, I. and Dequanter, D. (2018) Retrospective Analysis of 79 Patients with Orbital Floor Fracture: Outcomes and PatientReported Satisfaction. Archives of Craniofacial Surgery, 19, 108-113. https://doi.org/10.7181/acfs.2018.01837

[17] Krishna, D.S. and Soumadip, D. (2016) Reconstruction of Orbital Floor Fractures with Porous Polyethylene Implants: A Prospective Study. Journal of Maxillofacial and Oral Surgery, 15, 300-307. https://doi.org/10.1007/s12663-015-0840-Z

[18] Gas, C., Sidjilani, B.M., Dodart, L. and Boutault, F. (1999) Fractures isolées du plancher orbitaire. Revue de Stomatologie et de Chirurgie Maxillo-Faciale, 100, 27-33.

[19] Freund, M., Hahnel, S. and Sartir, K. (2002) The Value of Magnetic Resonance Imaging in the Diagnosis of Orbital Floor Fractures. European Radiology, 12, $1127-$ 1133. https://doi.org/10.1007/s00330-001-1167-3

[20] Shuttleworth, J.N., David, D.B., Potts, M.J., Belle, C.N. and Guest, P.G. (1999) Orbital Trauma: Do Not Blow Your Nose. British Medical Journal, 318, 1054-1055. https://doi.org/10.1136/bmj.318.7190.1054

[21] Roth, A., Desmangles, P. and Rossillion, B. (1999) Le traitement précoce des impotences musculaires secondaires aux fractures du plancher de l'orbite. Journal Français D'Ophtalmologie, 22, 645-650.

[22] Palmer, O.D., Whittaker, V. and Pinnock, C. (2006) Early Perioperative Care of the Acutely Injured Maxillo Facial Patients. Oral and Maxillofacial Surgery Clinics of North America, 18, 261-273. https://doi.org/10.1016/j.coms.2006.02.001

[23] Morax, S. and Bennilouche, P. (1998) Fractures par "Blow-out" en pathologie orbito palpébrale. Société Française do Ophtalmologie, 60, 715-772. 